\title{
OCONCEITO DE BACIA HIDROGRÁFICA E A IMPORTÂNCIA DA CARACTERIZAÇÃO MORFOMÉTRICA PARA O ENTENDIMENTO DA DINÂMICA AMBIENTAL LOCAL
}

Valter Luiz Iost Teodoro* Denilson Teixeira** Daniel Jadyr Leite Costa*** Beatriz Buda Fuller*

\section{Introdução}

A caracterização morfométrica de uma bacia hidrográfica é um dos primeiros e mais comuns procedimentos executados em análises hidrológicas ou ambientais, e tem como objetivo elucidar as várias questões relacionadas com o entendimento da dinâmica ambiental local e regional.

Segundo Antonelli e Thomaz (2007), a combinação dos diversos dados morfométricos permite a diferenciação de áreas homogêneas. Estes parâmetros podem revelar indicadores físicos específicos para um determinado local, de forma a qualificarem as alterações ambientais. Destacase também sua importância nos estudos sobre vulnerabilidade ambiental em bacias hidrográficas. Uma ampla revisão sobre variáveis morfométricas e sua aplicabilidade pode ser encontrada em Collares (2000).

A Política Nacional de Recursos Hídricos, instituída pela Lei no 9.433 , de 8 de janeiro de 1997, incorpora princípios e normas para a gestão de recursos hídricos adotando a definição de bacias hidrográficas como unidade de estudo

* Mestrando do Programa de Pós-Graduação em Desenvolvimento Regional e Meio Ambiente - UNIARA.

** Doutor em Ciências da Engenharia Ambiental, docente do Programa de Pós-Graduação em Desenvolvimento Regional e Meio Ambiente do Centro Universitário de Araraquara UNIARA.

*** Apoio técnico do Programa de Pós-Graduação em Desenvolvimento Regional e Meio Ambiente do Centro Universitário de Araraquara - UNIARA. 
e gestão. Assim, é de grande importância para gestores e pesquisadores a compreensão do conceito de bacia hidrográfica e de suas subdivisões.

Diversas definições de bacia hidrográfica foram formuladas ao longo do tempo. Percebe-se, nestes autores, grande semelhança e consideração deste recorte espacial, baseado na área de concentração de determinada rede de drenagem. Entretanto as definições que envolvem as subdivisões da bacia hidrográfica (sub-bacia e microbacia), apresentam abordagens diferentes tocando fatores que vão do físico ao ecológico.

Assim, as definições propostas para bacia hidrográfica assemelham-se ao conceito dado por Barrella (2001), sendo definido como um conjunto de terras drenadas por um rio e seus afluentes, formada nas regiões mais altas do relevo por divisores de água, onde as águas das chuvas, ou escoam superficialmente formando os riachos e rios, ou infiltram no solo para formação de nascentes e do lençol freático. As águas superficiais escoam para as partes mais baixas do terreno, formando riachos e rios, sendo que as cabeceiras são formadas por riachos que brotam em terrenos íngremes das serras e montanhas e à medida que as águas dos riachos descem, juntam-se a outros riachos, aumentando o volume e formando os primeiros rios, esses pequenos rios continuam seus trajetos recebendo água de outros tributários, formando rios maiores até desembocarem no oceano.

Lima e Zakia (2000), acrescentam ao conceito geomorfológico da bacia hidrográfica, uma abordagem sistêmica. Para esses autores as bacias hidrográficas são sistemas abertos, que recebem energia através de agentes climáticos e perdem energia através do deflúvio, podendo ser descritas em termos de variáveis interdependentes, que oscilam em torno de um padrão, e, desta forma, mesmo quando perturbadas por ações antrópicas, encontramse em equilíbrio dinâmico. Assim, qualquer modificação no recebimento ou na liberação de energia, ou modificação na forma do sistema, acarretará em uma mudança compensatória que tende a minimizar o efeito da modificação e restaurar o estado de equilíbrio dinâmico.

Os termos sub-bacia e microbacia hidrográfica também estão incorporados na literatura técnico-científica, todavia, não apresentam a mesma convergência conceitual apresentada para bacia hidrográfica conforme comentado.

As sub-bacias são áreas de drenagem dos tributários do curso d'água principal. Para definir sua área os autores utilizam-se de diferentes unidades de medida. Para Faustino (1996), as sub-bacias possuem áreas maiores que $100 \mathrm{~km}^{2}$ e menores que $700 \mathrm{~km}^{2}$, já para Rocha (1997, apud MARTINS et al., 2005), são áreas entre 20.000 ha e 30.000 ha (200 km2 a 300 km2). Para Santana (2004), bacias podem ser desmembradas em um número qualquer de sub-bacias, dependendo do ponto de saída considerado ao longo do seu eixo-tronco ou canal coletor. Cada bacia hidrográfica interliga-se com outra de ordem hierárquica superior, constituindo, em relação à última, uma sub-bacia Portanto, os termos bacia e sub-bacias hidrográficas são relativos.

Dentro dessas subdivisões da bacia, aparece também na literatura o termo microbacia. Uma série de conceitos são aplicados na definição de microbacias, podendo ser adotados critérios como unidades de medida, hidrológicos e ecológicos.

Para Santana (2003), o termo microbacia, embora difundido em nível nacional, constitui uma denominação empírica, sugerindo o autor a sua substituição por sub-bacia hidrográfica.

Já para Faustino (1996), a microbacia possui toda sua área com drenagem direta ao curso principal de uma sub-bacia, várias microbacias formam uma sub-bacia, sendo a área de uma microbacia inferior a $100 \mathrm{~km} 2$.

Cecílio e Reis (2006), definem a microbacia como uma sub-bacia hidrográfica de área reduzida, não havendo consenso de qual seria a área máxima (máximo varia entre 10 a 20.000 ha ou $0,1 \mathrm{~km} 2$ a $200 \mathrm{~km} 2$ ).

Do ponto de vista da hidrologia, a classificação de bacias hidrográficas em grandes e pequenas não é vista somente na sua superfície total, mas considerando os efeitos de certos fatores dominantes na geração do deflúvio, tendo as microbacias como características distintas uma grande sensibilidade tanto às chuvas de alta intensidade (curta duração), como também ao fator uso do solo (cobertura vegetal), sendo assim, as alterações na quantidade e qualidade da água do deflúvio, em função de chuvas intensas e ou em função de mudanças no solo, são detectadas com mais sensibilidade nas microbacias do que nas grandes bacias. Portanto, essa explicação contribui na distinção, definição e delimitação espacial de microbacias e bacias hidrográficas, sendo sua compreensão, crucial para a estruturação de programas de monitoramento ambiental, por meio de medições de variáveis hidrológicas, liminológicas, da topografia e cartografia e com o auxílio de sistemas de informações geográficas. Dessa forma, pode-se chegar a uma adequação espacial de microbacias e bacias hidrográficas (LIMA; ZAKIA, 2000).

Outro conceito importante atribuído a microbacias é o ecológico, que considera a menor unidade do ecossistema onde pode ser observada a delicada relação de interdependência entre os fatores bióticos e abióticos, sendo que perturbações podem comprometer a dinâmica de seu funcionamento. Esse conceito visa à identificação e o monitoramento de forma orientada dos impactos ambientais (MOSCA, 2003; LEONARDO, 2003).

Calijuri e Bubel (2006), adotam unidades hidrológicas e ecológicas para conceitualizarem o termo microbacia hidrográfica. Para os autores, são áreas 
formadas por canais de $1^{\mathrm{a}} \mathrm{e} 2^{\mathrm{a}}$ ordem e, em alguns casos, de $3^{\mathrm{a}}$ ordem, devendo ser definida como base na dinâmica dos processos hidrológicos, geomorfológicos e biológicos. As microbacias são áreas frágeis e freqüentemente ameaçadas por perturbações, nas quais as escalas espacial, temporal e observacional são fundamentais. Nos quadros 01,02 e 03 estão apresentados diferentes definições para bacia hidrográfica, sub-bacia hidrográfica e microbacia hidrográfica respectivamente.

Quadro 1. Diferentes conceitos de bacia hidrográfica encontrados na literatura.

\begin{tabular}{|c|c|}
\hline Autores & Conceito de Bacia hidrográfica \\
\hline $\begin{array}{l}\text { LIMA \& ZAKIA } \\
\qquad(2000)\end{array}$ & $\begin{array}{l}\text { São sistemas abertos, que recebem energia através de agentes } \\
\text { climáticos e perdem energia através do deflúvio, podendo ser } \\
\text { descritas em termos de variáveis interdependentes, que oscilam em } \\
\text { tomo de um padrão e, desta forma, mesmo quando perturbadas por } \\
\text { ações antrópicas, encontram-se em equilibrio dinâmico. Assim, } \\
\text { qualquer modificação no recebimento ou na liberação de energia, } \\
\text { ou modificação na forma do sistema, ocorrerá uma mudança } \\
\text { compensatória que tende a minimizar o efeito da modificação e } \\
\text { restaurar o estado de equilibrio dinâmico. }\end{array}$ \\
\hline $\begin{array}{l}\text { FERNANDES, } 1999 \\
\text { apud ATTANASIO, } \\
2004\end{array}$ & $\begin{array}{l}\text { O termo bacia hidrográfica refere-se a uma compartimentação } \\
\text { geográfica natural delimitada por divisores de água. Este } \\
\text { compartimento é drenado superficialmente por um curso d'água } \\
\text { principal e seus afluentes. }\end{array}$ \\
\hline $\begin{array}{c}\text { BORSATO\& } \\
\text { MARTONI (2004) }\end{array}$ & $\begin{array}{l}\text { Definida como uma área limitada por um divisor de águas, que a } \\
\text { separa das bacias adjacentes e que serve de captação natural da } \\
\text { água de precipitação através de superficies vertentes. Por meio de } \\
\text { uma rede de drenagem, formada por cursos d'água, ela faz } \\
\text { convergir os escoamentos para a seção de exutório, seu único ponto } \\
\text { de saída. }\end{array}$ \\
\hline $\begin{array}{l}\text { BARRELLA, W et al } \\
\text { (2007) }\end{array}$ & $\begin{array}{l}\text { Conjunto de terras drenadas por um rio e seus afluentes, formada } \\
\text { nas regiões mais altas do relevo por divisores de água, onde as } \\
\text { águas das chuvas, ou escoam superficialmente formando os riachos } \\
\text { e rios, ou infiltram no solo para formação de nascentes e do lençol } \\
\text { freático. As águas superficiais escoam para as partes mais baixas } \\
\text { do terreno, formando riachos e rios, sendo que as cabeceiras são } \\
\text { formadas por riachos que brotam em terrenos ingremes das serras e } \\
\text { montanhas e à medida que as águas dos riachos descem, juntam-se } \\
\text { a outros riachos, aumentando o volume e formando os primeiros } \\
\text { rios, esses pequenos rios continuam seus trajetos recebendo água } \\
\text { de outros tributários, formando rios maiores até desembocar no } \\
\text { oceano. }\end{array}$ \\
\hline $\begin{array}{l}\text { FAUSTINO } \\
\text { (1996) }\end{array}$ & $\begin{array}{l}\text { Sub-bacias são bacias com áreas maiores que } 100 \mathrm{~km}^{2} \mathrm{e} \text { menores } \\
\text { que } 700 \mathrm{~km}^{2} \text {. }\end{array}$ \\
\hline
\end{tabular}

Quadro 2. Diferentes conceitos de sub-bacias hidrográficas encontrados na literatura.

\begin{tabular}{|c|c|}
\hline Autores & Conceito de Sub-bacia \\
\hline $\begin{array}{l}\text { SANTANA } \\
\text { (2004) }\end{array}$ & $\begin{array}{l}\text { As bacias podem ser desmembradas em um número qualquer de } \\
\text { sub-bacias, dependendo do ponto de saida considerado ao longo } \\
\text { do seu eixo-tronco ou canal coletor. Cada bacia hidrográfica } \\
\text { interliga-se com outra de ordem hierárquica superior, } \\
\text { constituindo, em relação à última, uma sub-bacia. Portanto, os } \\
\text { termos bacia e sub-bacias hidrográficas são relativos. }\end{array}$ \\
\hline $\begin{array}{l}\text { ATTANASIO } \\
\text { (2004) }\end{array}$ & $\begin{array}{l}\text { Unidade fisica caracterizada como uma área de terra drenada por } \\
\text { um determinado curso d'água e limitada, perifericamente, pelo } \\
\text { chamado divisor de águas. }\end{array}$ \\
\hline $\begin{array}{l}\text { ROCHA apud } \\
\text { MARTINS et al } \\
(2005)\end{array}$ & $\begin{array}{l}\text { Sub - bacias são áreas entre } 20.000 \text { ha e } 30.000 \text { ha }\left(200 \mathrm{~km}^{2} \text { e } 300\right. \\
\left.\mathrm{km}^{2}\right) \text {. }\end{array}$ \\
\hline $\begin{array}{l}\text { FAUSTINO } \\
\text { (1996) }\end{array}$ & $\begin{array}{l}\text { A microbacia possui toda sua área com drenagem direta ao curso } \\
\text { principal de uma sub-bacia, várias microbacias formam uma sub- } \\
\text { bacia, sendo a área de uma microbacia inferior a } 100 \mathrm{~km}^{2} \text {. }\end{array}$ \\
\hline $\begin{array}{l}\text { BRASIL, } 1986 \text { apud } \\
\text { HEIN, } 2000\end{array}$ & $\begin{array}{l}\text { As microbacias são áreas fisiográficas drenadas por um curso } \\
\text { d'água ou para um sistema de cursos d'água conectados e que } \\
\text { convergem, direta ou indiretamente, para um leito ou para um } \\
\text { espelho d'água, constituindo uma unidade ideal para o } \\
\text { planejamento integrado do manejo dos recursos naturais do meio } \\
\text { ambiente por ele definido. }\end{array}$ \\
\hline $\begin{array}{l}\text { MOLDAN \& } \\
\text { CERNY, } 1994 \text { apud } \\
\text { MACHADO, } 2002\end{array}$ & $\begin{array}{l}\text { As microbacias são as menores unidades da paisagem capaz de } \\
\text { integrar todos os componentes relacionados com a disponibilidade } \\
\text { e qualidade de água como: atmosfera, vegetação natural, plantas } \\
\text { cultivadas, solo, rochas subjacentes, corpos d'água e paisagem } \\
\text { circundante. }\end{array}$ \\
\hline $\begin{array}{l}\text { LANNA, } 1995 \text { apud } \\
\text { BRAGA, } 2003\end{array}$ & $\begin{array}{l}\text { Microbacia hidrográfica é entendida como uma "área } \\
\text { geograficamente delimitada pelos divisores de água que } \\
\text { alimentam pequenos tributários". }\end{array}$ \\
\hline $\begin{array}{c}\text { MOSCA } \\
(2003)\end{array}$ & $\begin{array}{l}\text { Considera a microbacia como a menor unidade do ecossistema } \\
\text { onde pode ser observada a delicada relação de interdependência } \\
\text { entre os fatores bióticos e abióticos, sendo que perturbações } \\
\text { podem comprometer a dinâmica de seu funcionamento, sendo } \\
\text { assim, esse conceito visa à identificação e o monitoramento de } \\
\text { forma orientada dos impactos ambientais. }\end{array}$ \\
\hline $\begin{array}{l}\text { LEONARDO } \\
\text { (2003) }\end{array}$ & $\begin{array}{l}\text { A microbacia hidrográfica é um elemento de escala de análise } \\
\text { ambiental muito singular, pois representa o elo entre a escala } \\
\text { micro, correspondente àquele nivel de análise, verificação, } \\
\text { medição, monitoramento e intervenção in loco e a macroescala de } \\
\text { análise, que corresponde à paisagem, região, bacia hidrográfica, } \\
\text { nação ou até mesmo uma escala global, de onde são emanadas as } \\
\text { normas, a legislação e as politicas públicas. Dessa forma a } \\
\text { mesoescala de análise da sustentabilidade é a própria escala } \\
\text { espacial da microbacia hidrográfica. }\end{array}$ \\
\hline
\end{tabular}


Quadro 3. Diferentes conceitos de microbacias hidrográficas encontrados na literatura.

\begin{tabular}{|c|c|}
\hline Autores & Conceito de Microbacia \\
\hline $\begin{array}{l}\text { ATTANASIO } \\
\text { (2004) }\end{array}$ & $\begin{array}{l}\text { A microbacia é a unidade básica de planejamento para } \\
\text { compatibilização da preservação dos recursos naturais e da } \\
\text { produção agropecuária. As microbacias hidrográficas possuem } \\
\text { caracteristicas ecológicas, geomorfológicas e sociais } \\
\text { integradoras, o que possibilita a abordagem holistica e } \\
\text { participativa, envolvendo estudos interdisciplinares para o } \\
\text { estabelecimento de formas de desenvolvimento sustentável } \\
\text { inerentes ao local e região onde forem implementados. }\end{array}$ \\
\hline $\begin{array}{l}\text { SANTANA } \\
(2004)\end{array}$ & $\begin{array}{l}\text { O termo microbacia, embora difundido em nível nacional, } \\
\text { constitui uma denominação empirica, sugerindo o autor a sua } \\
\text { substituição por sub-bacia hidrográfica. }\end{array}$ \\
\hline $\begin{array}{l}\text { CALIJURI \& } \\
\text { BUBEL } \\
(2006)\end{array}$ & $\begin{array}{l}\text { Microbacias são áreas formadas por canais de } 1^{a} \text { e } 2^{a} \text { ordem e, } \\
\text { em alguns casos, de } 3^{a} \text { ordem, devendo ser definida como base } \\
\text { na dinâmica dos processos hidrológicos, geomorfológicos e } \\
\text { biológicos. As microbacias são áreas frágeis e freqüentemente } \\
\text { ameaçadas por perturbações, nas quais as escalas espacial, } \\
\text { temporal e observacional são fundamentais. }\end{array}$ \\
\hline
\end{tabular}

O presente trabalho segue as definições de Mosca, Leonardo (2003), pois essas permitem compreender a relação entre as ações antrópicas e o ecossistema microbacia de forma sistêmica, permitindo a elaboração de sugestões que possam mitigar os impactos ambientais e dessa maneira garantir a utilização sustentável de recursos naturais.

A microbacia hidrográfica oferece, portanto, a vantagem de um gerenciamento simultâneo, interdependente e cumulativo de seus aspectos econômicos, sociais e ambientais, através da possibilidade de realizar um planejamento e administração integrada dos recursos naturais, solo e água, ampliando assim, notavelmente, a sinergia e a potencialidade dos processos operados, além de oferecer condições geográficas e sociais favoráveis à organização comunitária (RYFF, 1995 apud SABANÉS, 2002).

O comportamento hidrológico de uma bacia hidrográfica é função de suas características geomorfológicas (forma, relevo, área, geologia, rede de drenagem, solo, etc.) e do tipo da cobertura vegetal existente (LIMA, 1976). Assim, as características físicas e bióticas de uma bacia possuem importante papel nos processos do ciclo hidrológico, influenciando, dentre outros, a infiltração e quantidade de água produzida como deflúvio, a evapotranspiração, os escoamentos superficial e sub- superficial. Além disso, o comportamento hidrológico de uma bacia hidrográfica também é afetado por ações antrópicas, uma vez que, ao intervir no meio natural, o homem acaba interferindo nos processos do ciclo hidrológico (TONELLO, 2005).

Neste contexto, as características morfométricas do padrão de drenagem e do relevo refletem algumas propriedades do terreno, como infiltração e deflúvio das águas das chuvas, e expressam estreita correlação com a litologia, estrutura geológica e formação superficial dos elementos que compõem a superfície terrestre (PISSARA et al., 2004).

Asclassesde informaçõesmorfológicasdeterminamdiferençasessenciais entre distintas paisagens, como relatam estudos clássicos desenvolvidos por Horton (1945), Strahler (1957), França (1968), Christofoletti (1978), entre outros.

Segundo Tonello (2005), as características morfométricas podem ser divididas em: características geométricas, características do relevo e características da rede de drenagem (Tabela 1).

Tabela 1. Características morfométricas de bacias hidrográficas.

\begin{tabular}{|c|c|}
\hline Características Morfométricas & Tipo de Análises \\
\hline Características geométricas & $\begin{array}{l}\text { Área total } \\
\text { Perímetro total } \\
\text { Coeficiente de compacidade (Kc) } \\
\text { Fator de forma (F) } \\
\text { Índice de circularidade (IC) } \\
\text { Padrão de drenagem }\end{array}$ \\
\hline Caracteristicas do relevo & $\begin{array}{l}\text { Orientação } \\
\text { Declividade mínima } \\
\text { Declividade média } \\
\text { Declividade máxima } \\
\text { Altitude mínima } \\
\text { Altitude média } \\
\text { Altitude máxima } \\
\text { Declividade média do curso d'água principal }\end{array}$ \\
\hline Características da rede de drenagem & $\begin{array}{l}\text { Comprimento do curso d'água principal } \\
\text { Comprimento total dos cursos d'água } \\
\text { Densidade de drenagem (Dd) } \\
\text { Ordem dos cursos d'água }\end{array}$ \\
\hline
\end{tabular}

Fonte: Tonello (2005). 


\section{Objetivos}

A presente pesquisa teve como objetivo apresentar diferentes conceitos de bacia hidrográfica e realizar a caracterização morfométrica da microbacia do córrego Marivan.

\section{Metodologia}

\section{Área de estudo}

Araraquara localiza-se na região central do Estado de São Paulo, a $270 \mathrm{~km}$ da capital por via rodoviária, sendo o eixo principal do município a Rodovia Washington Luís. A bacia hidrográfica do rio Jacaré-Guaçu possui, como os mais importantes afluentes, o ribeirão das Cruzes junto com o ribeirão do Ouro. Segundo o Departamento Autônomo de Água e Esgoto do Município de Araraquara (DAAE), o ribeirão das Cruzes, localizado a noroeste da cidade, possui uma sub-bacia de $173 \mathrm{~km} 2$ dentro do perímetro urbano e recebe a contribuição dos córregos do Marivan, Serralhal, Cupim, Paiol, Laranjal e do ribeirão do Lajeado. É responsável por $30 \%$ do abastecimento público do município de Araraquara, desembocando diretamente no rio Jacaré-Guaçu, afluente direto do rio Tietê. O rio Jacaré-Guaçu por sua vez é um importante afluente do rio Tietê, sendo assim o ribeirão das Cruzes e o córrego do Marivan situam-se na bacia hidrográfica dos rios Jacaré-Guaçu e Tietê, pertencendo assim à Unidade de Gerenciamento de Recursos Hídricos Tietê-Jacaré (UGRHI 13).

O córrego Marivan, pequeno afluente do ribeirão das Cruzes, pode contribuir com uma vazão menor que as dos córregos Águas do Paiol, Laranjal, e ribeirão do Lajeado, todavia, esses se situam a jusante da captação de água do município de Araraquara, enquanto o córrego Marivan situa-se a montante da captação de água, portanto, é imprescindível no auxílio do abastecimento de água do município. O córrego do Marivan, localizado a nordeste da cidade com $1,37 \mathrm{~km}$ de extensão, integra à sub-bacia do ribeirão das Cruzes, com uma microbacia de aproximadamente $2,1 \mathrm{~km} 2$ e perímetro de $5,37 \mathrm{~km}$.
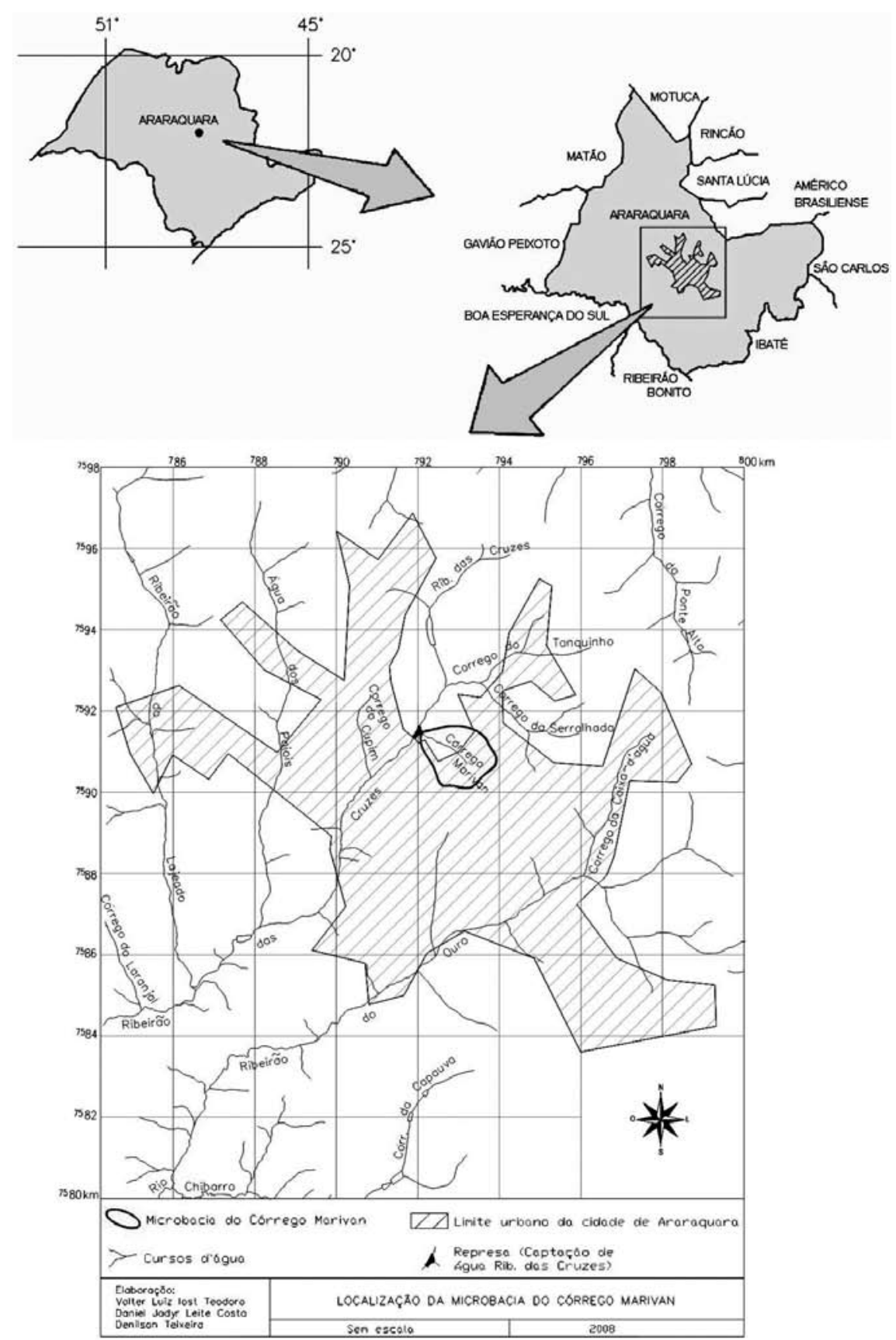

Figura 1. Localização do município de Araraquara (SP) e da microbacia do córrego Marivan. 
A microbacia do córrego Marivan apresenta atualmente $70 \%$ de sua área urbanizada sendo caracterizada por uma ocupação de fins comerciais e residenciais e a parte restante é ocupada por parcelas de uso rural e áreas de proteção permanentes, todavia, esses dados estão em transformação pois em julho de 2007, parte da área destinada ao uso rural foi desmembrada para implantação de um novo loteamento, dessa forma, em um curto período de tempo, mais de $70 \%$ da área da microbacia será urbanizada e menos de $30 \%$ destinado a agricultura e áreas de proteção permanente. A FIGURA 2 apresenta as áreas urbana e rural, os bairros com os respectivos nomes e a área de preservação permanente (APP Legal) que deveria existir, de acordo com a Lei no 4.771/65 do Código Florestal, na microbacia do córrego Marivan.

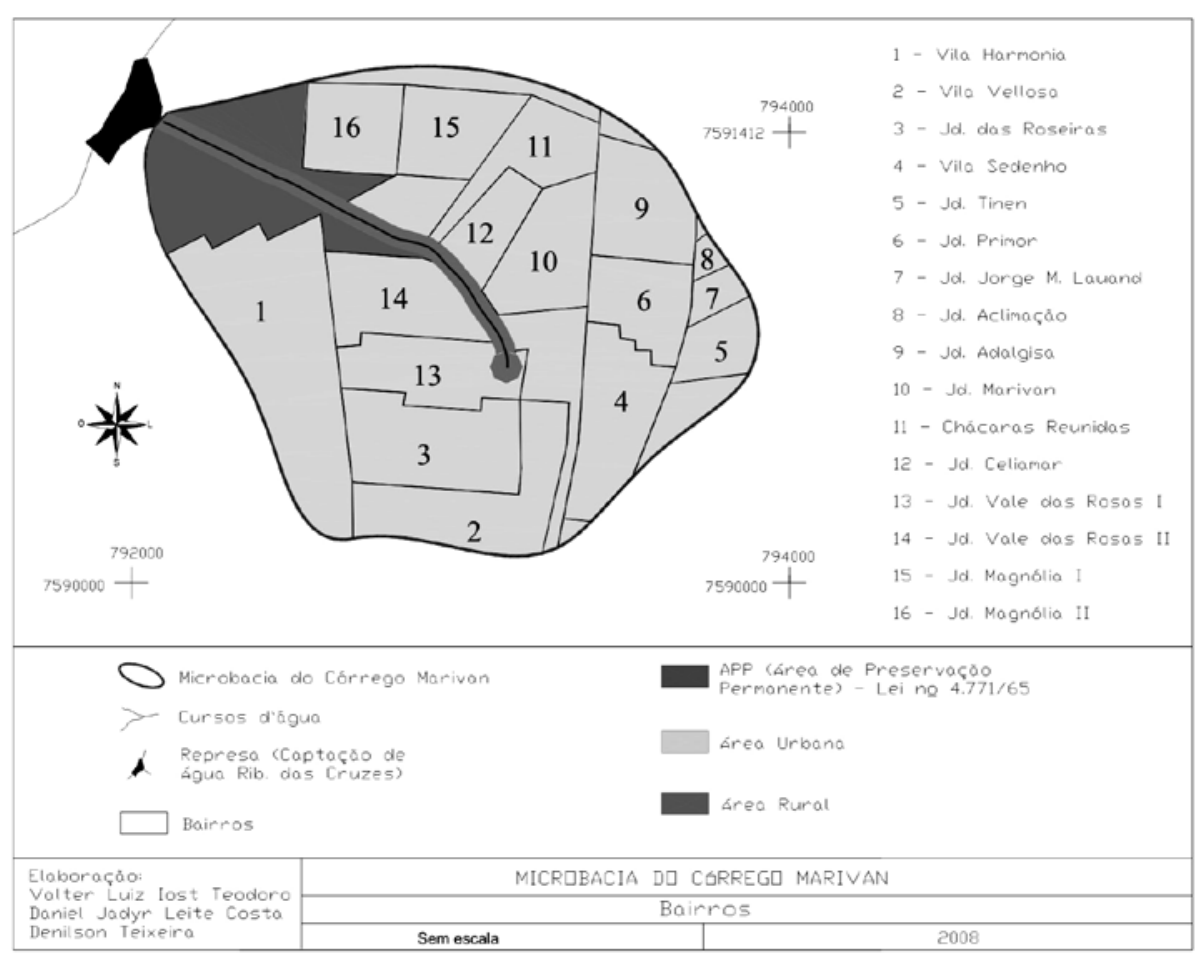

Figura 2. Microbacia hidrográfica do córrego Marivan - Araraquara (SP).
Amicrobaciapossui 02 bosques, bosquedo Rotary, comaproximadamente 450 árvores plantadas e uma área de reflorestamento conhecida como bosque da Maçonaria. Existem seis setores censitários do IBGE localizados na área de abrangência da microbacia (setores: $83,84,85,86,87$ e 159), de modo que a população total nestes setores, para o ano 2000, era de aproximadamente 4.000 habitantes. A microbacia possui uma Unidade Básica de Saúde (Programa de Saúde da Família), denominada Adolfo Léo, responsável pelo atendimento de 853 famílias cadastradas, que residem dentro dos limites da microbacia do córrego Marivan (DATASUS, 2007).

$\mathrm{Na}$ área de educação os munícipes são assistidos pela escola estadual de ensino médio Letícia de Godoy Bueno Carvalho Lopes.

A microbacia possui rede de iluminação em toda sua extensão urbana e quase $100 \%$ de suas ruas e avenidas pavimentadas. Contam ainda com a circulação de ônibus urbano, com linhas bairro-centro e centro-bairro. Existem dois postos de combustíveis situados a montante da nascente do córrego Marivan.

\section{Morfometria}

O levantamento cartográfico e a delimitação da bacia hidrográfica da área em estudo foram efetuados com base no mapa topográfico em escala 1:10.000, cedido pelo DAAE.

As fórmulas para obtenção dos parâmetros morfométricos são encontradas em Antoneli e Thomaz (2007), Christofolletti (1969), Villela e Mattos (1975), Tonello (2005) e Cardoso (2006) e estão apresentadas a seguir.

\section{Características geométricas}

a) Área: Toda área drenada pelo sistema pluvial inclusa entre seus divisores topográficos, projetada em plano horizontal, sendo elemento básico para o cálculo de diversos índices morfométricos (TONELLO, 2005).

b) Perímetro: Comprimento da linha imaginária ao longo do divisor de águas (TONELLO, 2005).

c) Fator de forma: Relaciona a forma da bacia com a de um retângulo, correspondendo a razão entre a largura média e o comprimento axial da bacia (da foz ao ponto mais longínquo do espigão), podendo ser influenciada por algumas características, principalmente pela geologia. Podem atuar também sobre alguns processos hidrológicos ou sobre o comportamento hidrológico da bacia. O fator de forma pode ser descrito pela seguinte equação (VILLELA; MATTOS 1975): 
$F=\frac{A}{L^{2}}$

Sendo: $F=$ fator de forma; $A=$ área de drenagem e $L=$ comprimento do eixo da bacia.

d) Coeficiente de compacidade: Relaciona a forma da bacia com um círculo. Constitui a relação entre o perímetro da bacia e a circunferência de um círculo de área igual ao da bacia (CARDOSO et al., 2006). Esse coeficiente é um número adimensional que varia com a forma da bacia, independentemente de seu tamanho. Quanto mais irregular for a bacia, maior será o coeficiente de compacidade. Um coeficiente mínimo igual a uma unidade corresponderia a uma bacia circular e, para uma bacia alongada, seu valor é significativamente superior a um, podendo ser calculado na seguinte equação (VILLELA; MATTOS 1975):

$K c=0,28 \times \frac{P}{\sqrt{A}}$

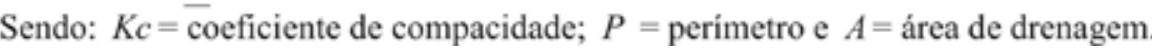

e) Índice de circularidade: Simultaneamente ao coeficiente de compacidade, o índice de circularidade tende para unidade à medida que a bacia aproxima-se a forma circular e diminui a medida que a forma torna alongada, segundo a equação (CARDOSO et al., 2006):

$$
I C=\frac{12,57 \times A}{P^{2}}
$$

Sendo: $I C=$ indice de circularidade; $A=$ área de drenagem e $P=$ perímetro

f) Densidade hidrográfica é a relação existente entre o número de rios ou cursos d'água e a área da bacia hidrográfica expressa pela fórmula:

$$
D h=\frac{N}{A}
$$

Sendo: $D h=$ densidade hidrográfica; $N=$ número de rios ou cursos d'água e $A=$ área de drenagem.
A finalidade deste índice é comparar a freqüência ou a quantidade de cursos d'água existentes em um área de tamanho padrão, como por exemplo o quilômetro quadrado (CRHISTOFOLETTI, 1969).

\section{Características de relevo}

a) Declividade: A declividade relaciona-se com a velocidade em que se dá o escoamento superficial, afetando, portanto, o tempo que leva a água da chuva para concentrar-se nos leitos fluviais que constituem a rede de drenagem das bacias, sendo que os picos de enchente, infiltração e susceptibilidade para erosão dos solos dependem da rapidez com que ocorre o escoamento sobre os terrenos da bacia (VILLELA; MATTOS, 1975).

b) Altitude: A variação de altitude associa-se com a precipitação, evaporação e transpiração, consequentemente sobre o deflúvio médio. Grandes variações de altitude numa bacia acarretam diferenças significativas na temperatura média, a qual, por sua vez, causa variações na evapotranspiração. Mais significativas, porém, são as possíveis variações de precipitação anual com a elevação.

c) Amplitude altimétrica: é a variação entre a altitude máxima e altitude mínima.

\section{Características da rede de drenagem}

a) Ordem dos cursos d'água: Consiste no processo de se estabelecer a classificação de determinado curso d'água (ou da área drenada que lhe pertence) no conjunto total da bacia hidrográfica na qual se encontra. Segundo Cardoso et al. (2006), Robert E. Horton, em 1945, foi quem propôs de modo mais preciso, os critérios para ordenação dos cursos d'água. Sendo os canais de primeira ordem aqueles que não possuem tributários; os canais de segunda ordem só recebem tributários de primeira ordem; os de terceira ordem podem receber um ou mais tributários de segunda ordem, mas também receber de primeira ordem; os de quarta ordem recebem tributários de terceira ordem e também de ordem inferior e assim sucessivamente. Segundo o mesmo autor, outra metodologia para descrever a ordem dos cursos d'água da bacia foi proposta por Arthur N. Strahler, em 1952, onde os menores canais sem tributários são considerados de primeira ordem; os canais de segunda ordem surgem da confluência de dois canais de primeira ordem, e só recebem afluentes de primeira ordem; os canais de terceira ordem surgem da confluência de dois canais de segunda ordem, podendo receber afluentes de segunda e primeira ordens; os canais de quarta ordem surgem da confluência de canais de terceira ordem, podendo receber tributários de ordens inferiores, assim sucessivamente. 
b) Densidade de drenagem: Segundo Crhistofoletti (1969), correlaciona o comprimento total dos canais ou rios com a área da bacia hidrográfica. Para calcular o comprimento devem ser medidos tanto os rios perenes como os temporários, definida por Horton (1945), pode ser calculada pela seguinte equação: drenagem.

$$
D d=\frac{L}{A}
$$

$A$
endo: $D d=$ densidade de drenagem; $L=$ comprimento total dos rios ou canais e $A=$ área de

O comportamento hidrológico das rochas, em um mesmo ambiente climático, vai repercutir a densidade de drenagem, ou seja, onde a infiltração é mais dificultada há maior escoamento superficial, gerando possibilidades maiores para esculturação de canais permanentes e consequentemente densidade de drenagem mais elevada.

c) Índice de sinuosidade: É a relação entre o comprimento do canal principal e a distância vetorial entre os extremos do canal (ALVES; CASTRO, 2003). A expressão para o cálculo do Índice de sinuosidade é descrita pelos autores como:

$$
I s=\frac{L}{D v}
$$

Sendo: $I s=$ indice de Sinuosidade; $L=$ comprimento do canal principal e $D v=$ distância vetorial do canal principal.

\section{Resultados e discussão}

A microbacia do córrego Marivan é de $2^{\mathrm{a}}$ ordem, indicando ser pouco ramificada, com uma área de $2,11 \mathrm{~km}^{2}$ e perímetro de $5,37 \mathrm{~km}$. O comprimento do canal principal é de $1,37 \mathrm{~km}$ com uma rede de drenagem total de $1,43 \mathrm{~km}$. A densidade de drenagem é de $0,68 \mathrm{~km} / \mathrm{km}^{2}$, indicando dessa forma que a microbacia possui uma baixa capacidade de drenagem.

A densidade de drenagem é um fator importante na indicação do grau de desenvolvimento do sistema de drenagem de uma bacia. Sendo assim, este índice, fornece uma indicação da eficiência da drenagem da bacia, sendo expressa pela relação entre o somatório dos comprimentos de todos os canais da rede; sejam eles perenes, intermitentes ou temporários; e a área total da bacia (ANTONELI; THOMAZ, 2007).

Christofoletti (1969), destaca que valores menores que $7,5 \mathrm{~km} / \mathrm{km} 2$ apresentam baixa densidade de drenagem. Valores entre 7,5 e 10,0 km/km2 apresentam média densidade. Já valores acima de $10,0 \mathrm{~km} / \mathrm{km} 2$, apresentam alta densidade hidrográfica. A bacia em estudo apresenta baixa densidade de drenagem, ou seja, apresenta um relevo pouco declivoso com rampas longas e solos profundos com alta capacidade de infiltração, exceto nas áreas próximas a foz, onde o relevo apresenta vertentes curtas e declivosas.

Já de acordo com Villela e Mattos (1975), esse mesmo índice (Densidade de drenagem), pode variar de $0,5 \mathrm{~km} / \mathrm{km} 2 \mathrm{em}$ bacias com drenagem pobre, a $3,5 \mathrm{~km} / \mathrm{km} 2$, ou mais, em bacias bem drenadas, indicando, também, que a bacia em estudo possui baixa capacidade de drenagem.

A densidade hidrográfica também é baixa, 0,95 canais $/ \mathrm{km}^{2}$, ou seja, menos de 1 canal por $\mathrm{km}^{2}$. O fator de forma é de 1,07 e o índice de circularidade de 0,91 , indicando que o perímetro da bacia aproxima-se a um círculo, favorecendo os processos de inundação (cheias rápidas), pois há maiores possibilidades de chuvas intensas ocorrerem simultaneamente em toda sua extensão, concentrando grande volume de água no tributário principal (CARDOSO et al., 2006). O Índice de sinuosidade próximo a 1 indicam que os canais tendem a serem retilíneos, já os valores superiores a 2,0, indicam que os canais tendem a ser tortuosos e os valores intermediários indicam formas transicionais, regulares e irregulares, dessa forma, o córrego Marivan possui um canal retilíneo e, segundo Antoneli e Thomaz (2007), esse tipo de canal favorece um maior transporte de sedimento.

Os resultados da caracterização morfométrica do Marivan estão apresentados na tabela 3 .

Tabela 3. Parâmetros morfométricos da microbacia do Marivan.

\begin{tabular}{|l|c|}
\hline \multicolumn{1}{|c|}{ Parâmetros } & Valores e Unidades \\
\hline Área & $2,11\left(\mathrm{~km}^{2}\right)$ \\
\hline Perimetro & $5,37(\mathrm{~km})$ \\
\hline Comprimento do canal principal & $1,37(\mathrm{~km})$ \\
\hline Comprimento vetorial do canal principal & $1,31(\mathrm{~km})$ \\
\hline Comprimento do tributário & $0,06(\mathrm{~km})$ \\
\hline Comprimento total da rede de drenagem & $1,43(\mathrm{~km})$ \\
\hline Altitude máxima & $685(\mathrm{~m})$ \\
\hline Altitude mínima & $615(\mathrm{~m})$ \\
\hline Amplitude altimétrica & $70(\mathrm{~m})$ \\
\hline Ordem do córrego & $2^{\mathrm{a}}$ \\
\hline Densidade de drenagem & $0,68\left(\mathrm{~km} / \mathrm{km}^{2}\right)$ \\
\hline Densidade hidrográfica & $0,95\left(\mathrm{canais} / \mathrm{km}^{2}\right)$ \\
\hline Índice de sinuosidade & 1,04 \\
\hline Fator de forma & 1,07 \\
\hline Coeficiente de compacidade & 1,03 \\
\hline Índice de circularidade & 0,91 \\
\hline
\end{tabular}

REVISTA UNIARA, n.20, 2007 


\section{Considerações finais}

O conceito de bacia hidrográfica cada vez mais vem sendo utilizado, como uma unidade ecossistêmica, na área de planejamento ambiental. Dentro desta abordagem, as características físicas de uma bacia, segundo Villela e Mattos (1975), constituem elementos de grande importância para avaliação de seu comportamento hidrológico, pois, ao estabelecerem-se relações e comparações entre eles e dados hidrológicos conhecidos, pode-se determinar indiretamente os valores hidrológicos em locais nos quais faltem dados. Christofoletti (1969) ressalta ainda que, a análise de aspectos relacionados à drenagem, relevo e geologia pode levar à elucidação e compreensão de diversas questões associadas à dinâmica ambiental local. Cabe lembrar que nenhum desses índices, isoladamente, deve ser entendido como capaz de simplificar a complexa dinâmica da bacia, a qual inclusive tem magnitude temporal.

\section{Referências:}

ALVES, J.M.P; CASTRO, P.T.A. Influência de feições geológicas na morfologia da bacia do rio do Tanque (MG) baseada no estudo de parâmetros morfométricos e análises de padrões de lineamentos. Rev. Brasileira de Geociências, p. 117-1245, jun. 2003.

ANTONELI, V; THOMAZ, E.L. Caracterização do meio físico da bacia do Arroio Boa Vista, Guamiranga-PR. Rev. Caminhos da Geografia, Uberlândia, v.8, n.21, p46-58, jun. 2007.

\section{ATTANASIO, C.M. Planos de manejo integrado de microbacias} hidrográficas com uso agrícola: uma abordagem hidrológica na busca da sustentabilidade. 2004. 193p. Tese (Doutorado em Recursos Florestais) - Escola Superior de Agricultura "Luis de Queiroz", Universidade de São Paulo, Piracicaba, 2004

BARRELLA, W. et al. As relações entre as matas ciliares os rios e os peixes. In: RODRIGUES, R.R.; LEITÃO FILHO; H.F. (Ed.) Matas ciliares:

conservação e recuperação. 2.ed. São Paulo: Editora da Universidade de São Paulo, 2001.

CALIJURI, M.C.; BUBEL, A.P.M. Conceituação de Microbacias. In: LIMA, W de P.; ZAKIA, M.J.B. (Orgs.) As florestas plantadas e a água. Implementando o conceito da microbacia hidrográfica como unidade de planejamento. São Carlos: Ed. RiMA, 2006. 226p.
CARDOSO, C.A. et al. Caracterização morfométrica da bacia hidrográfica do rio Debossan, Nova Friburgo-RJ. Árvore, Viçosa, v.30, n.2, p.241-248, 2006.

CECÍLIO,R.A.; REIS,E.F. Apostila didática: manejo de bacias hidrográficas. Universidade Federal do Espírito Santo, Centro de Ciências Agrárias, Departamento de Engenharia Rural, 2006. 10p.

CHRISTOFOLETTI, A. A morfologia de bacias de drenagem. Notícias Geomorfológicas, Campinas, v.18, n.36, p.130-2, 1978.

COLLARES, E.G. Avaliação de alterações em redes de drenagem de sub-bacias como subsídio ao zoneamento geoambiental de bacias hidrográficas: aplicação na bacia hidrográfica do Rio Capivari-SP. 2000 211p. Tese (Doutorado em Geotecnia) - Universidade de São Paulo, São Carlos, 2000.

COSTA, T.T.C et al. Vulnerabilidade ambiental em sub-bacias hidrográficas no estado do Rio de Janeiro por meio da integração temática da perda do solo (USLE), variáveis morfométricas e o uso/cobertura. In: SIMPÓSIO DE SENSORIAMENTO REMOTO, 13, 2007, Florianópolis. Anais..., Florianópolis, 2007. p. 2493-2500.

CRISTOFOLETTI, A. Análise morfométrica de bacias hidrográficas. Rev. Geomorfol, Campinas, v.18, n.9, p.35-64, 1969.

DAAE. Bacias Hidrográficas de Araraquara. Disponível em: www. daaeararaquara.com.br. Acesso em: 24 mar. 2007.

DATASUS. Banco de dados: Departamento de Informática do SUS Cadastro Nacional de Estabelecimentos de Saúde. Disponível em: www. cnes.datasus.gov.br. Acesso em: 18 mar. 2007.

FAUSTINO, J. Planificación y gestión de manejo de cuencas. Turrialba: CATIE, 1996. 90p.

FRANÇA, G.V. de. Interpretação fotográfica de bacias e de redes de drenagem aplicada a solos da região de Piracicaba. Piracicaba, 1968. 151p. Tese (Doutorado) - Escola Superior de Agricultura "Luiz de Queiroz", Universidade de São Paulo, 1968 
HEIN, M. Espacialização de duas microbacias hidrográficas do rio Piracicaba para modelagem hidrológica. 2000. 291p. Dissertação (Mestrado em Engenharia Agrícola) - Feagri, Universidade Estadual de Campinas, Campinas, 2000.

HORTON, R.E. Erosinal development of streams and their drainage basin: Hydrophysical approach to quantitative morphology. Geol. Soc America Bulletin, v.3, n.56, 1945

LANA, C.L.; ALVES, J.M. de P.; CASTRO, P de T.A. Análise morfométrica da bacia do rio Tanque, MG-Brasil. Rev. Escola de Minas, Ouro Preto, v.54, n.2, 2001.

LEONARDO, H.C.L.Indicadores de qualidade de solo e água para avaliação do uso sustentável da microbacia hidrográfica do rio Passo CUE, região oeste do Estado do Paraná. 2003. 121p. Dissertação

(Mestrado em Recursos Florestais) - Escola Superior de Agricultura "Luis de Queiroz”, Universidade de São Paulo, Piracicaba, 2003.

LIMA, W.P. Prinsípios de manejo de bacias hidrográficas. Piracicaba: ESALQ. USP, 1976.

LIMA, W.P.; ZAKIA M.J.B. Hidrologia de matas ciliares. In: RODRIGUES; R.R.; LEITÃO FILHO; H.F. (Ed.) Matas ciliares: conservação e recuperação. 2.ed. São Paulo: Editora da Universidade de São Paulo, 2000. p.33-43.

LINDENER, E.A.; GOMIG, K.; KOBIYAMA, M. Sensoriamento remoto aplicado à caracterização morfométrica e a classificação do uso do solo na bacia rio do Peixe/SC. In: SIMPÓSIO DE SENSORIAMENTO REMOTO, 13, 2007, Florianópolis. Anais..., Florianópolis, 2007, p.3405-12.

MACEDO, M.F. Avaliação do sistema de monitoramento dos recursos hídricos e da viabilidade técnica, legal e econômica da aplicação da resolução CONAMA 357/2005 para a sub-bacia do ribeirão das Cruzes (Araraquara-SP). 2007. 97p. Dissertação (Mestrado em Desenvolvimento Regional e Meio Ambiente) - Centro Universitário de Araraquara UNIARA, Araraquara, 2007.
MACHADO, R.E. Simulação de escoamento e produção de sedimento em uma microbacia hidrográfica utilizando técnicas de modelagem e geoprocessamento. 2002. 152p. Tese (Doutorado em Agronomia) - Escola Superior de Agricultura “Luiz de Queiroz”, Universidade de São Paulo, Piracicaba, 2002.

MARTINS, F.B. et al. Zoneamento Ambiental da sub - bacia hidrográfica do Arroio Cadena, Santa Maria (RS). Estudo de caso. Cerne, Lavras, v.11, n.3, p.315-322, jul./set. 2005.

MOSCA, A.A.O. Caracterização hidrológica de duas microbacias visando a identificação de indicadores hidrológicos para o monitoramento ambiental de manejo de florestas plantadas. 2003. 96p. Dissertação (Mestrado em Recursos Florestais) - Escola Superior de Agricultura “Luis de Queiroz", Universidade de São Paulo, Piracicaba, 2003.

PISSARA, T.C.T.; POLITANO, W.; FERRAUDO, A.S. Avaliação de características morfométricas na relação solo-superfície da bacia hidrográfica do córrego Rico, Jaboticabal (SP). Rev. Bras. Ciências do Solo, Viçosa, n.28, p.297-305, 2004.

SABANÉS, L. Manejo sócio-ambiental de recursos naturais e políticas públicas: um estudo comparativo dos projetos "Paraná Rural e Microbacias”. 2002. Dissertação (Mestrado em Desenvolvimento Rural) Faculdade de Ciências Econômicas, UFRGS, Porto Alegre, 2002.

SANTANA, D.P. Manejo Integrado de Bacias Hidrográficas. Sete Lagoas Embrapa Milho e Sorgo, 2003. 63p. (Embrapa Milho e Sorgo. Documentos, $30)$.

STRAHLER AN. Quantitative analysis of watershed geomorphology. Trans Am Geophys Union n.38, p.913-920, 1957

TONELLO, K.C. Análise hidroambiental da bacia hidrográfica da cachoeira das Pombas, Guanhães, MG. 2005. 69p. Tese (Doutorado em Ciências Florestal) - Universidade Federal de Viçosa, Viçosa, 2005.

VALE, A.R. Expansão urbana e plurifuncionalidade no espaço periurbano do município de Araraquara (SP). 2005. 221p. Tese (Doutorado em Geografia) - Instituto de Geociências e Ciências Exatas, Universidade Estadual Paulista, Rio Claro, 2005.

REVISTA UNIARA, n.20, 2007 
VILLELA, S.M.; MATTOS, A. Hidrologia aplicada. São Paulo: McGRAWHill do Brasil, 1975. 245p.

\section{Resumo:}

A presente pesquisa teve como objetivo apresentar os diferentes conceitos relativos a bacias hidrográficas e realizar a caracterização morfométrica da microbacia do córrego Marivan localizada no município de Araraquara (SP). Diferentes definições referentes ao conceito de bacias hidrográficas foram discutidas e sistematizadas. Para a caracterização morfométrica da microbacia do córrego Marivan foi utilizado um mapa topográfico na escala 1:10.000 cedido pelo Departamento Autônomo de Água e Esgoto de Araraquara (DAAE). Os resultados indicam que a microbacia do córrego Marivan é pouco ramificada, com uma área de $2,1 \mathrm{~km}^{2}$ e perímetro de $5,37 \mathrm{~km}$. O comprimento do canal principal é de 1,37 km com uma rede de drenagem total de 1,43 km. Possui uma baixa capacidade de drenagem e densidade hidrográfica. $\mathrm{O}$ fator de forma e o índice de circularidade indicam que o perímetro da bacia aproxima-se a um círculo, o que favorece os processos de inundação (cheias rápidas). Concluise que a análise de aspectos relacionados à drenagem, relevo e geologia pode levar à elucidação e compreensão de diversas questões associadas à dinâmica ambiental local, todavia nenhum desses índices, isoladamente, deve ser entendido como capaz de simplificar a complexa dinâmica da bacia, a qual inclusive tem magnitude temporal.

\section{Palavras-chave:}

Bacia hidrográfica, Sub-bacia, Microbacia, Caracterização Morfométrica, Córrego Marivan.

\section{RESÍDUOS DE SERVIÇOS DE SAÚdE GERADOS EM UNIDADES DE SAÚDE DE PEQUENO PORTE NO MUNICÍPIO DE JAÚ- SP: GERAÇÃO E DISPOSIÇÃO FINAL}

\author{
Neusa Regina P. Simões de Castro* \\ Marcus César A.A. de Castro** \\ Maria Lúcia Ribeiro** \\ Maria Lúcia Rissato* \\ Luciana Camargo de Oliveira***
}

\section{Introdução}

Entre os diferentes tipos de resíduos sólidos e semi-sólidos gerados pelo homem, os produzidos nos serviços de saúde têm merecido destaque nos últimos anos, particularmente, pelo aumento do número de estabelecimentos de saúde, e surgimento de patologias como AIDS (Síndrome da imunodeficiência adquirida) e Hepatite B e C (TAKAYANAGUI, 1993; MOREL, 2000).

Resíduos de Serviços de Saúde (RSS) são aqueles gerados por prestadores de assistência médica, odontológica, laboratorial, farmacêutica, instituições de ensino e pesquisa, relacionados à assistência humana e animal (BRASIL, 2005).

Os resíduos de serviços de saúde, mesmo representando pequena parte dos resíduos produzidos no Brasil (cerca de $2 \%$ do total de resíduos), possuem relevância devido ao impacto causado tanto na saúde pública quanto ao meio ambiente, por serem uma fonte potencial de organismos patogênicos, produtos tóxicos, inflamáveis, perfurocortantes e radioativos. Os resíduos de serviços de saúde podem ser classificados como sendo de grande ou pequeno porte dependendo da quantidade de resíduo gerado. Os estabelecimentos de saúde

* Mestre do Programa de Mestrado em Desenvolvimento Regional e Meio Ambiente do Centro Universitário de Araraquara - UNIARA.

** Professores Doutores Docentes do Programa de Mestrado em Desenvolvimento Regional e Meio Ambiente do Centro Universitário de Araraquara - UNIARA.

***Doutora em Química e Pesquisadora do Programa de Mestrado em Desenvolvimento Regional e Meio Ambiente do Centro Universitário de Araraquara - UNIARA. 